\title{
Correction to: Suspended sediment load prediction using artificial neural network and ant lion optimization algorithm
}

\author{
Fatemeh Barzegari Banadkooki ${ }^{1} \cdot$ Mohammad Ehteram $^{1,2} \cdot$ Ali Najah Ahmed $^{3}$ (D) Fang Yenn Teo $^{4}$. \\ Mahboube Ebrahimi ${ }^{1}$. Chow Ming Fai ${ }^{5}$. Yuk Feng Huang ${ }^{6}$. Ahmed El-Shafie ${ }^{7,8}$
}

Published online: 23 July 2020

(C) Springer-Verlag GmbH Germany, part of Springer Nature 2020

\section{Correction to: Environmental Science and Pollution Research https://doi.org/10.1007/s11356-020-09876-w}

Following the publication of the article (Banadkooki et al. 2020) it has come to the authors' attention that Figure 9 should be corrected. In addition, the first panel of Figure 11 has been repeated with the second panel. Therefore, the authors would like to make the following modification: Changing the caption for Figure 9 to "Sensitivity analysis for the data splitting ratio, a) Training Data and b) Testing Data" and replacing the Figure 9 with the new one as shown Figure 1.

Replacing first panel of Fig. 1 with the corrected one as shown herein in Fig. 9. The new panel of Fig. 9 shows the $d$ value for the uncertainty analysis. The required explanations to present the findings from this panel remain unchanged in the original article.

Publisher's note Springer Nature remains neutral with regard to jurisdictional claims in published maps and institutional affiliations.

The online version of the original article can be found at https://doi.org/ 10.1007/s11356-020-09876-w

\section{Ali Najah Ahmed}

mahfoodh@uniten.edu.my

1 Agricultural Department, Payam Noor University, Tehran, Iran

2 Department of Water Engineering and Hydraulic Structures, Faculty of Civil Engineering, Semnan University, Semnan, Iran

3 Institute of Energy Infrastructure (IEI), Universiti Tenaga Nasional (UNITEN), 43000 Kajang, Selangor, Malaysia

4 Faculty of Science and Engineering, University of Nottingham Malaysia, 43500 Semenyih, Selangor, Malaysia
5 Institute of Sustainable Energy (ISE), Universiti Tenaga Nasional (UNITEN), 43000 Kajang, Selangor, Malaysia

6 Department of Civil Engineering, Lee Kong Chian Faculty of Engineering and Science, Universiti Tunku Abdul Rahman, 43200 Kajang, Selangor, Malaysia

7 Department of Civil Engineering, Faculty of Engineering, University of Malaya (UM), 50603 Kuala Lumpur, Malaysia

8 National Water Center, United Arab Emirates University, $15551 \mathrm{Al}$ Ain, United Arab Emirates 
Fig. 11 Sensitivity analysis for the data splitting ratios
1.4

1.2

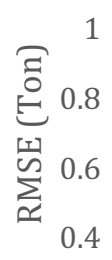

0.2

0

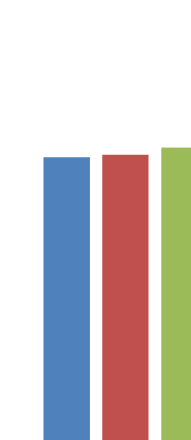

Narmab station

Tamar station
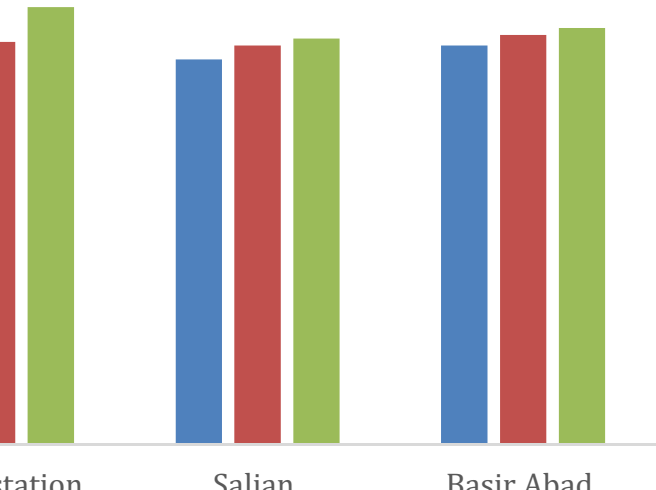

Basir Abad

- $70 \% \quad$ - $60 \% \quad-80 \%$

(a) Training Data

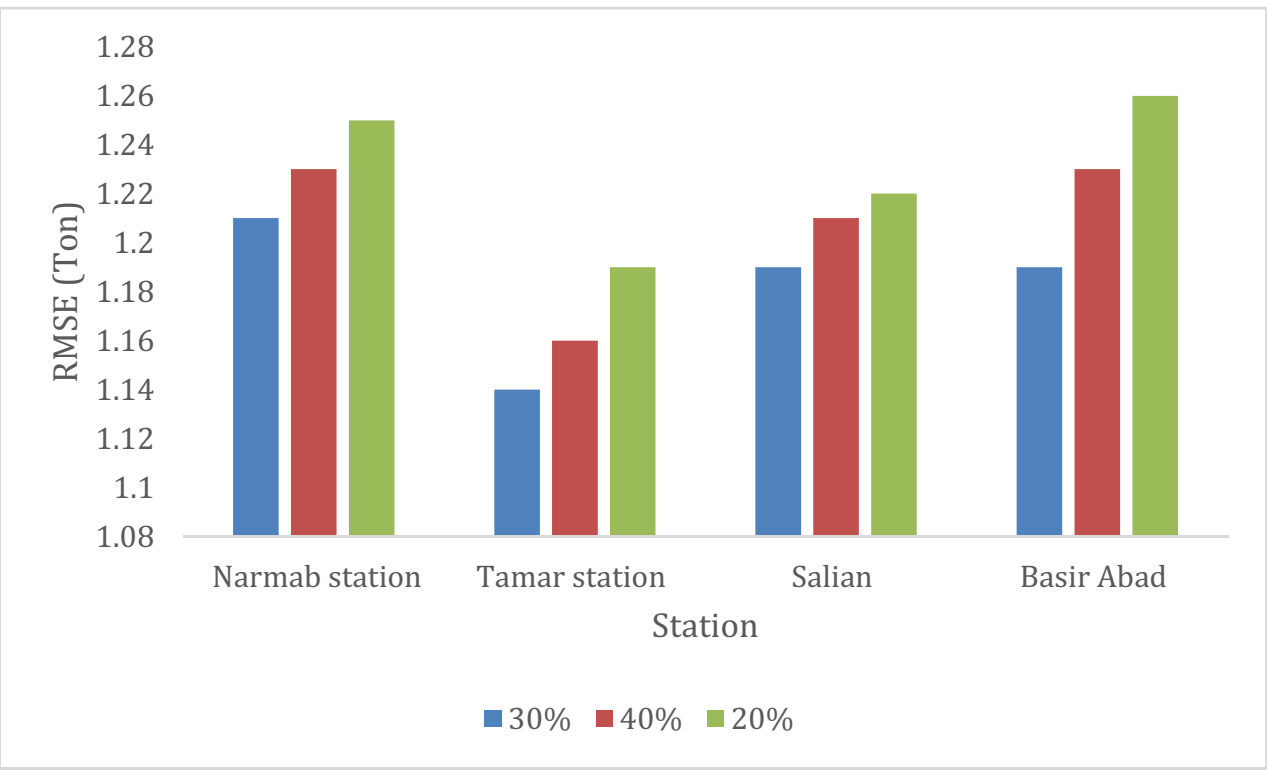

(b) Testing Data 
Fig. 9 Uncertainty analysis for the proposed SSL models

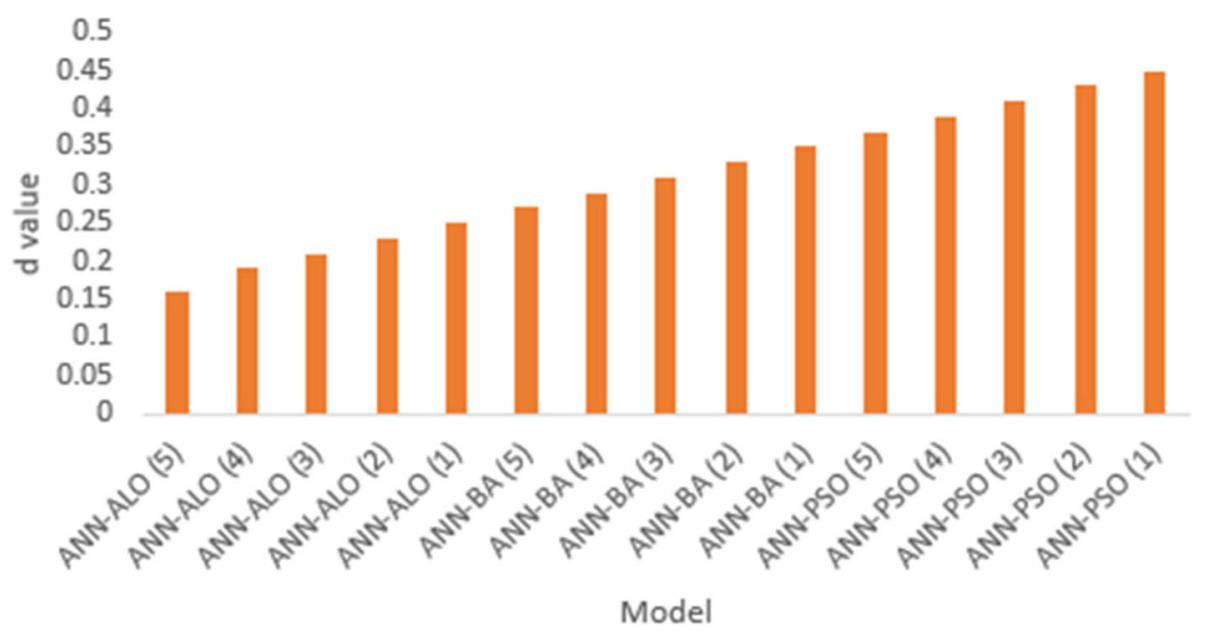

ad

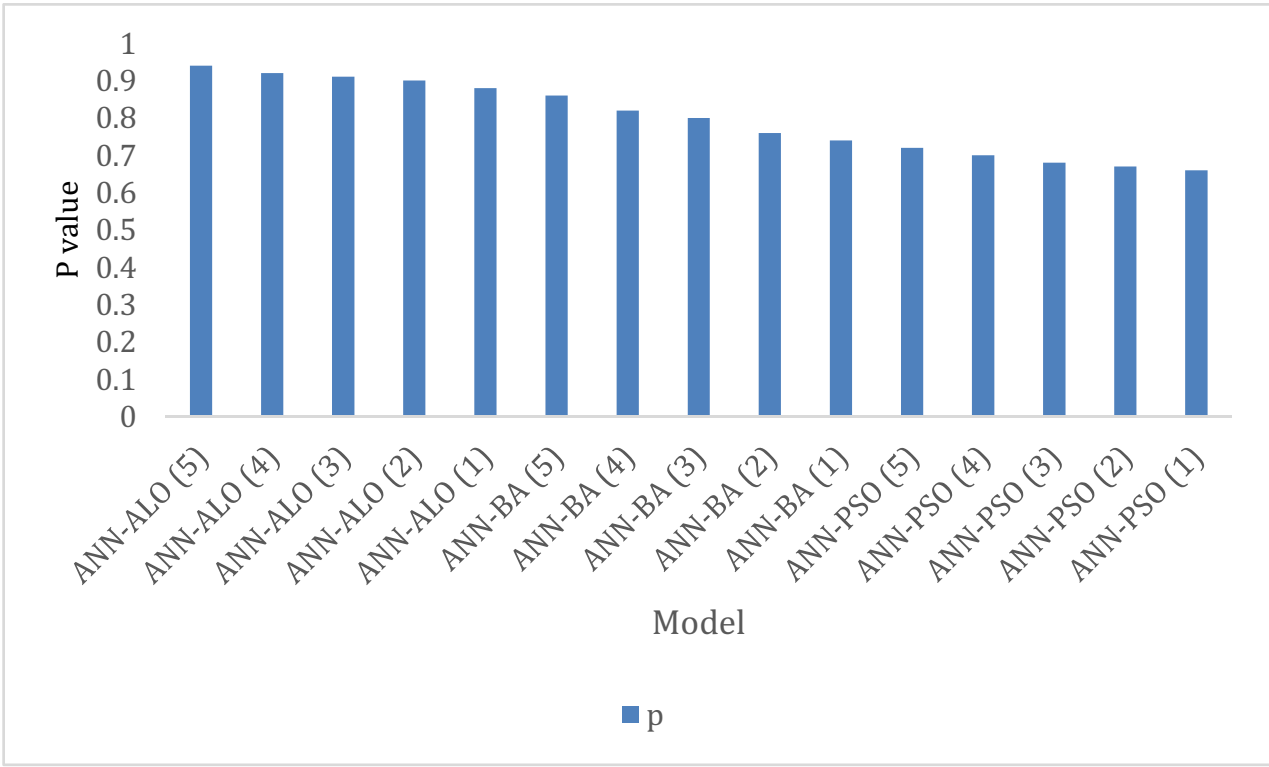

